\title{
Vitamin $\mathrm{K}_{\mathbf{2}}$ induces phosphorylation of protein kinase $\mathrm{A}$ and expression of novel target genes in osteoblastic cells
}

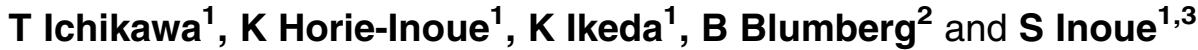 \\ ${ }^{1}$ Division of Gene Regulation and Signal Transduction, Research Center for Genomic Medicine, Saitama Medical University, Hidaka-shi, Saitama 350-1241, Japan \\ ${ }^{2}$ Department of Developmental and Cell Biology, University of California, Irvine, California 92697-2300, USA \\ ${ }^{3}$ Department of Geriatric Medicine, Graduate School of Medicine, The University of Tokyo, 7-3-1 Hongo, Bunkyo-ku, Tokyo 113-8655, Japan \\ (Correspondence should be addressed to S Inoue; Email: inoue-ger@h.u-tokyo.ac.jp)
}

\begin{abstract}
Vitamin $\mathrm{K}$ is known as a critical nutrient required for bone homeostasis and blood coagulation, and it is clinically used as a therapeutic agent for osteoporosis in Japan. Besides its enzymatic action as a cofactor of vitamin K-dependent $\gamma$-glutamyl carboxylase (GGCX), we have previously shown that vitamin $\mathrm{K}_{2}$ is a transcriptional regulator of bone marker genes and extracellular matrix-related genes, by activating the steroid and xenobiotic receptor (SXR). To explore a novel action of vitamin $\mathrm{K}$ in osteoblastic cells, we identified genes up-regulated by a vitamin $\mathrm{K}_{2}$ isoform menaquinone-4 (MK-4) using oligonucleotide microarray analysis. Among these up-regulated genes by MK-4, growth differentiation factor 15 (GDF15) and stanniocalcin 2 (STC2) were identified as novel MK-4 target genes independent of GGCX and SXR pathways in human and mouse osteoblastic cells. The induction of GDF15 and STC2 is likely specific to MK-4, as it was not exerted by another vitamin $\mathrm{K}_{2}$ isoform MK-7, vitamin $\mathrm{K}_{1}$, or the MK-4 side chain structure geranylgeraniol. Investigation of the involved signaling pathways revealed that MK-4 enhanced the phosphorylation of protein kinase $A$ (PKA), and the MK-4-dependent induction of both GDF15 and STC2 genes was reduced by the treatment with a PKA inhibitor $\mathrm{H} 89$ or siRNA against PKA. These results suggest that vitamin $\mathrm{K}_{2}$ modulates its target gene expression in osteoblastic cells through the PKA-dependent mechanism, which may be distinct from the previously known vitamin $\mathrm{K}$ signaling pathways.
\end{abstract}

Journal of Molecular Endocrinology (2007) 39, 239-247

\section{Introduction}

Vitamin Ks are fat-soluble 2-methyl-1,4-naphthoquinone-related compounds, including natural phylloquinone $\left(\mathrm{K}_{1}\right)$ and menaquinones $\left(\mathrm{K}_{2}\right)$. Vitamins $\mathrm{K}_{1}$ and $\mathrm{K}_{2}$ differ only in the substituent group. Vitamin $K_{1}$ possesses a phytyl group (partially saturated polyisoprenoid group), whereas $\mathrm{K}_{2}$ possesses a repeating, unsaturated trans-polyisoprenyl group. Menaquinones include a range of related forms generally designated as menaquinone- $n$ (MK- $n)$, where $n$ is the number of isoprenyl groups. Vitamin Ks play a role in the bonebuilding process as well as classic blood coagulation pathway. Indeed, clinical studies have demonstrated that vitamin $\mathrm{K}_{2}$ is an effective treatment for osteoporosis and preventing fractures (Booth et al. 2000, Shiraki et al. 2000). Menaquinone-4 (MK-4), one of the vitamin $\mathrm{K}_{2}$ containing four isoprene units, is frequently prescribed for osteoporosis in Japan.

One of the notable molecular functions of vitamin $\mathrm{K}$ is as a cofactor for vitamin $\mathrm{K}$-dependent $\gamma$-glutamyl carboxylase (GGCX). GGCX catalyzes the post-translational modification of specific glutamates to $\gamma$-carboxyglutamate (Gla) in a number of proteins.
Most vitamin K-dependent proteins are involved in the hemostatic process and are associated with bone metabolism. Osteocalcin (bone Gla protein), and matrix Gla protein (MGP) are two major Gla proteins in bone and $\gamma$-carboxylated proteins are important in bone metabolism. Osteocalcin serves as a good biochemical marker of the metabolic turnover of bone because osteocalcin lacking Gla residues cannot bind to hydroxyapatite, one of the major components of bone matrix (Nishimoto \& Price 1985, Vergnaud et al. 1997). Moreover, levels of undercarboxylated osteocalcin increase during aging and significantly correlate with fracture risk (Vergnaud et al. 1997).

MGP is predominantly expressed and produced in chondrocytes and vascular smooth muscle cells (Luo et al. 1997, Shanahan \& Weissberg 1998). Data from rodent studies revealed that MGP plays a key role in the inhibition of tissue calcification. Luo et al. (1997) reported that MGP-deficient mice showed excessive cartilage formation and growth plate mineralization, resulting in impaired growth of the long bones. Thus, vitamin $\mathrm{K}$ plays a significant role in bone homeostasis through $\gamma$-carboxylated proteins. On the other hand, we previously reported that vitamin $K_{2}$ has a 
transcriptional regulatory function in addition to its role as an enzyme cofactor (Tabb et al. 2003). Vitamin $\mathrm{K}_{2}$ was a ligand of the steroid and xenobiotic receptor (SXR), and both vitamin $\mathrm{K}_{2}$ and the known SXR ligands rifampicin (RIF) up-regulated expression of the prototypical SXR target gene cytochrome P450 (CYP) $3 \mathrm{~A} 4$ and bone marker genes, such as alkaline phosphatase and osteoprotegerin (Tabb et al. 2003). Furthermore, we identified SXR-dependent vitamin $\mathrm{K}_{2}$ target genes that participated in extracellular matrix formation in osteoblastic cells (Ichikawa et al. 2006). These findings suggested an important role for vitamin $\mathrm{K}_{2}$-dependent transcriptional regulation in bone homeostasis. Meanwhile, during our microarray analyses that identify the $S X R$ target genes using osteoblastic cells treated with RIF or vitamin $\mathrm{K}_{2}$, we found that a number of genes were specifically up-regulated by vitamin $\mathrm{K}_{2}$ but not RIF. This observation suggested that potentially novel mechanism could be associated with the up-regulation of these genes by vitamin $\mathrm{K}_{2}$.

In the present study, we screened for genes induced by MK-4 in osteoblastic MG63 cells using microarray analysis, and identified several vitamin $\mathrm{K}_{2}$-target genes. Here, we focused on the growth differentiation factor 15 (GDF15) and stanniocalcin 2 (STC2) genes as MK-4 targets. We found that other vitamin Ks, geranylgeraniol (GGO), and SXR agonists failed to induce the expression of GDF15 and STC2 genes, although a protein kinase A (PKA) activator forskolin (FSK) induced the expression of both genes. Our findings indicate that GDF15 and STC2 are regulated by a PKAdependent, GGCX- and SXR-independent pathways.

\section{Materials and methods}

\section{Materials}

RIF was purchased from Nacalai Tesque (Kyoto, Japan). Vitamin $\mathrm{K}_{1}$, GGO, and FSK were purchased from Sigma. MK-4 and MK-7 were gifts of Eisai Co. Ltd (Tokyo, Japan). H89 was obtained from BioMol (Plymouth Meeting, PA, USA).

\section{Cell culture and generation of stable cell lines expressing SXR}

MG63 human osteosarcoma cells were grown in Dulbecco's modified Eagle's medium supplemented with $10 \%$ fetal bovine serum (FBS), $50 \mathrm{U} / \mathrm{ml}$ penicillin, and $50 \mu \mathrm{g} / \mathrm{ml}$ streptomycin. Mouse MC3T3-E1 osteoblastic cells were maintained in $\alpha$-minimum essential medium (MEM) supplemented with $10 \% \mathrm{FBS}, 50 \mathrm{U} / \mathrm{ml}$ penicillin, and $50 \mu \mathrm{g} / \mathrm{ml}$ streptomycin. Prior to vitamin $\mathrm{K}$ treatment, cells were cultured in phenol red-free

Table 1 Common up-regulated genes by 48-h treatment with menaquinone-4 (MK-4; $10 \mu \mathrm{M})$ in both MG63/vector and MG63/FlagVP16C-SXR stable cell lines identified by GeneChip analysis

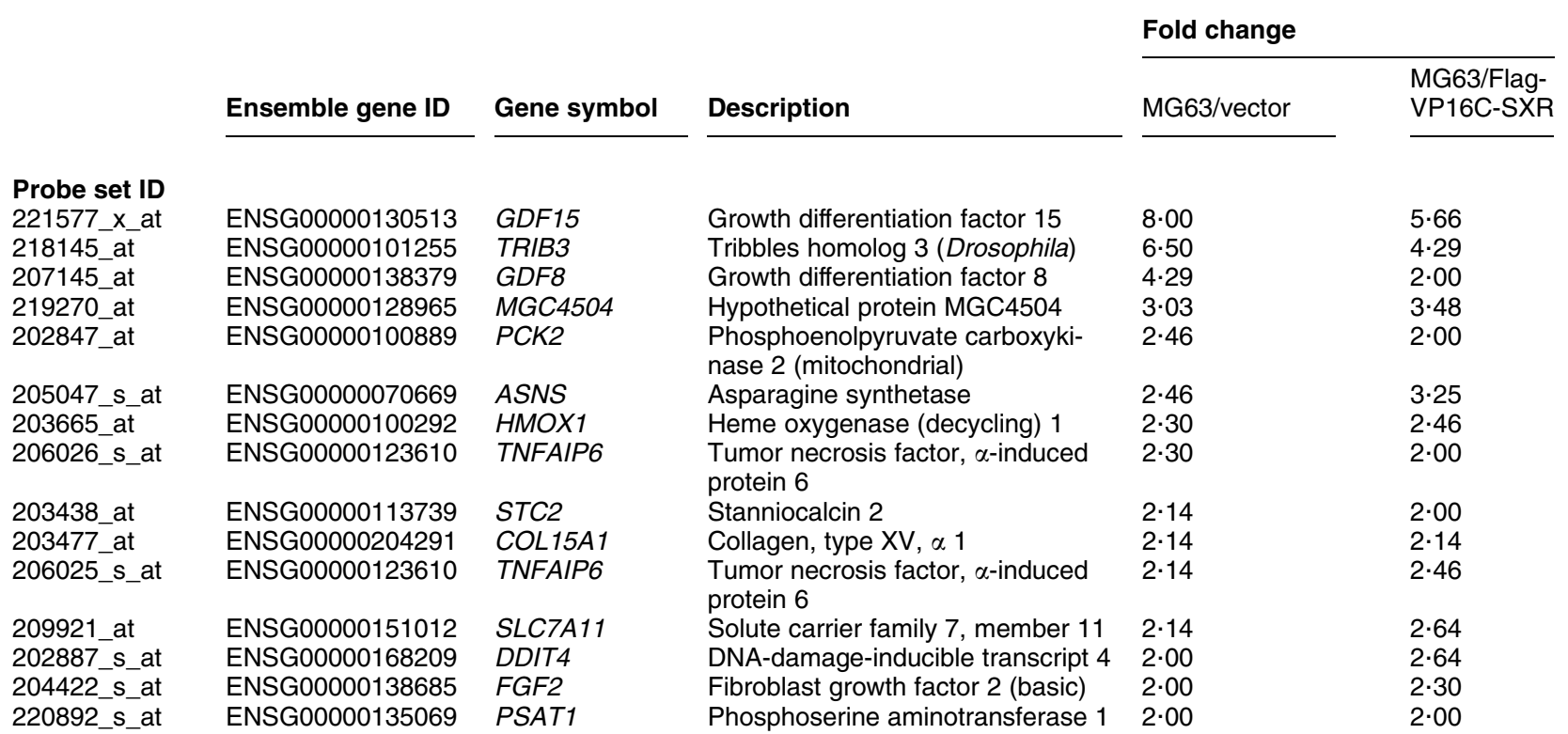

MG63/vector and MG63/Flag-VP16C-SXR cells are stably expressing Flag-pcDNA3 vector and pcDNA3-Flag-VP16C-SXR respectively. Twofold or more up-regulated genes by MK- 4 over vehicle in both cells were selected, except SXR-dependent up-regulated ones with the ratios of fold change in MG63/FlagVP16C-SXR versus MG63/vector by $\geq 1.5$-fold. Gene annotation was determined based on the probe set ID by the Array Finder on the Affymetrix web site (http://www.affymetrix.com). 
media containing $10 \%$ dextran-charcoal stripped FBS (dcc-FBS). N-terminally Flag-tagged pcDNA3 (Invitrogen) plasmids containing VP16C-SXR (pcDNA3Flag-VP16C-SXR) were previously described (Ichikawa et al. 2006). VP16C-SXR contained 20 amino acids from the C-terminus of VP16 activation domain upstream of SXR. Generation of MG63 cell lines stably expressing pcDNA3-Flag-VP16C-SXR (MG63/Flag-VP16C-SXR) or the empty vector Flag-tagged pcDNA3 (MG63/vector) were previously described (Ichikawa et al. 2006).

\section{Western blot analysis}

Whole cell lysates were prepared using a lysis buffer (50 mM HEPES (pH 7.5), $150 \mathrm{mM} \mathrm{NaCl,} \mathrm{10 \%} \mathrm{glycerol,}$

A MG63
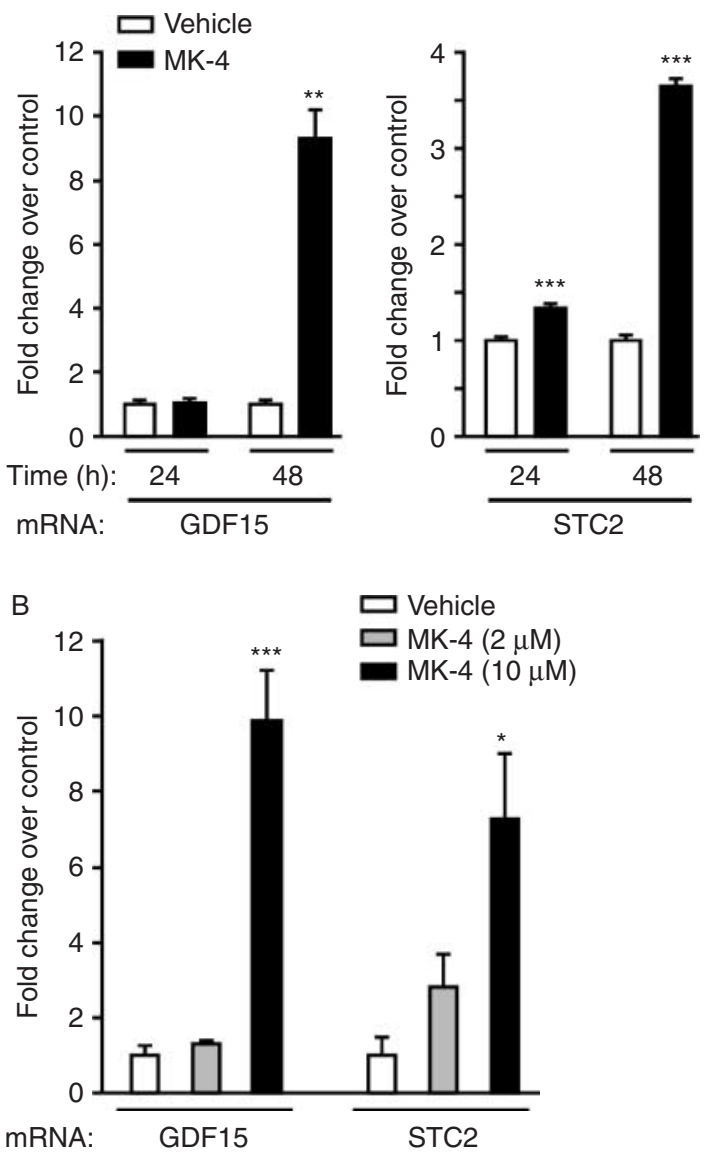

Figure 1 Up-regulation of growth differentiation factor 15 (GDF15) and stanniocalcin-2 (STC2) mRNA levels by a vitamin $\mathrm{K}_{2}$ isoform menaquinone-4 (MK-4) in osteoblastic cells. Human osteoblastic MG63 cells were treated with MK-4 $(10 \mu \mathrm{M})$ or vehicle for the indicated times $(A)$, and mouse osteoblastic MC3T3-E1 cells were treated with MK-4 (2 or $10 \mu \mathrm{M})$ or vehicle for $48 \mathrm{~h}(\mathrm{~B})$. mRNA levels for GDF15 and STC2 were determined by quantitative RT-PCR (qRT-PCR). Data are representative of experiments with similar results, each performed in triplicate. ${ }^{\star} P<0.05,{ }^{\star \star} P<0.01$,

${ }^{\star \star \star} P<0.001$ when compared with control cells treated with vehicle.
$1 \%$ Triton $\mathrm{X}-100,1.5 \mathrm{mM} \mathrm{MgCl}_{2}, 1 \mathrm{mM}$ sodium orthovanadate, $10 \mu \mathrm{g} / \mathrm{ml}$ aprotinin, and $10 \mu \mathrm{g} / \mathrm{ml}$ leupeptin). Protein concentrations were analyzed using the BCA protein assay kit (Pierce Biotechnology, Rockford, IL, USA). Proteins were resolved by SDS-PAGE and electroblotted onto Immobilon-P Transfer Membrane (Millipore, Billerica, MA, USA). The antibody-antigen complexes were detected using the Western Blotting Chemiluminescence Luminol Reagent (Santa Cruz Biotechnology, Santa Cruz, CA, USA). Antibodies used included anti-phospho PKA and anti-PKA (Cell Signaling Technology, Danvers, MA, USA).

\section{Preparation of cRNA and oligonucleotide array hybridization}

Total RNA was extracted from MG63/vector and MG63/Flag-VP16C-SXR cells treated with vehicle $(0 \cdot 1 \%$ ethanol $)$ and MK-4 $(10 \mu \mathrm{M})$ for $48 \mathrm{~h}$. The methods for preparation of cRNA and subsequent steps leading to hybridization and scanning of the U133A GeneChip Arrays Station (Affymetrix, Santa Clara, CA, USA) were performed as described previously (Ichikawa et al. 2006). Data analysis was performed using Affymetrix Microarray Suite software. For comparing arrays, normalization was performed using data from all probe sets.

\section{Quantitative reverse transcription PCR analysis}

Osteoblastic cells were treated with RIF, MK-4, MK-7, vitamin $\mathrm{K}_{1}$, GGO, FSK, or vehicle for indicated times. Total RNA was isolated using the ISOGEN reagent (Nippon gene, Tokyo, Japan). First, strand cDNA was generated from RNase-free DNase I-treated total RNA using the SuperScript II Reverse Transcriptase (Invitrogen) and oligo-d $\mathrm{T}_{20}$ primer. For PCR amplification, the primer sequences were: human GDF15, 5'-GAAACGCTACGAGGACCTGCTA-3' ${ }^{\prime}$ and 5'-ACGAGGTCGGTGTTCGAATC-3'; human STC2, $5^{\prime}$-TGGGATTTGCATGACTTTTCTG-3' and $5^{\prime}$-GGCGTCTTTGATGAATGACTTG-3'; human GGCX, 5'-CTTGAGACCCTTTGAGGCAGTT- $3^{\prime}$ and $5^{\prime}$-GGATTTGACTCAGGAGGATTAGAATG-3'; human CYP3A4, 5' -TTCAGCCCATCTCCTTTCATATTT- $3^{\prime}$ and $5^{\prime}$-CAGTTGGGTGTTGAGGATGGA-3'; human $\alpha$-catalytic subunit of PKA (PRKACA), 5'-CAACTTTCCGTTCCTCGTCAA- ${ }^{\prime}$ and 5'-CGCCGGGCACGTACTC-3'; human glyceraldehyde-3phosphate dehydrogenase (GAPDH), 5'-GCCTGCCTGACCAAATGC- $3^{\prime}$ and $5^{\prime}$-GTGGTCGTTGAGGGCAATG$3^{\prime}$; mouse GDF15, 5'-AGACTGTGCAGGCAACTCTTGA$3^{\prime}$ and $5^{\prime}$-ACACTCGCCCACGCACAT- $3^{\prime}$; mouse STC2, $5^{\prime}$-CAACTCTTGTGAAATCCAGGGTTT-3' and 5'-CATCGAATTTTCCAGCGTTGT- ${ }^{\prime}$; and mouse GAPDH, 5'-GCATGGCCTTCCGTGTTC-3' and 5'-TGTCATCAT- 
132\# ACTTGGCAGGTTTCT-3' . mRNAs were quantified by real-time PCR using SYBR green PCR master mix (Applied Biosystems, Foster City, CA, USA) and the ABI Prism 7000 system (Applied Biosystems) as previously described (Ichikawa et al. 2006).

\section{RNA interference}

Small interfering RNA (siRNA) duplexes to target human GGCX (D-009856-02) and PRKACA (D-004649-01) were purchased from Dharmacon Research Inc. (Lafayette, CO, USA). An siRNA specific to luciferase gene (Luciferase GL2 Duplex, Dharmacon) was used as a control. Cells were transfected with siRNA using GeneSilencer reagent (Genlantis, San Diego, CA, USA) for indicated times in the culture medium containing $10 \%$ dcc-FBS in the presence or absence of MK-4.

\section{Statistical analysis}

Differences between two groups were analyzed using two-sample, two-tailed Student's $t$-test. A $P$ value $<0.05$ was considered to be significant. All data are presented in the text and figures as the mean \pm s.D.

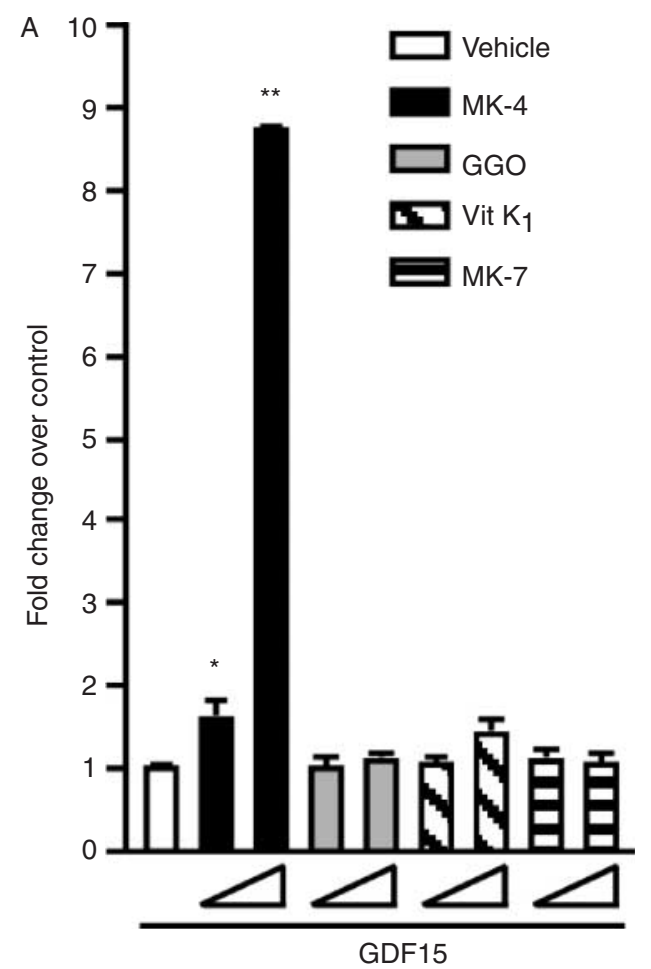

\section{Results}

\section{Identification of genes up-regulated by MK-4 in osteoblastic cells by microarray analysis}

To identify up-regulated genes by MK-4 treatment in osteoblastic cells, we prepared biotin-labeled cRNA samples from MG63 cells expressing empty FlagpcDNA3 (MG63/vector) or Flag-VP16C-SXR (MG63/Flag-VP16C-SXR) treated with vehicle $(0 \cdot 1 \%$ ethanol) or MK-4 $(10 \mu \mathrm{M})$. The Affymetrix U133A GeneChip array represents more than 18000 human transcripts from $\sim 14000$ genes. Gene expression analysis for the MG63 samples was performed by hybridizing aliquots of cRNA $(10 \mu \mathrm{g}$ each $)$ to the GeneChip arrays. Eighty-five transcripts were induced twofold or greater by MK-4 in MG63/vector cells, whereas 77 transcripts were induced in MG63/Flag-VP16C-SXR cells. In the present study, we focused on the SXRindependent gene expression in osteoblastic cells, by screening the common up-regulated genes (greater than or equal to twofold) in both vector and Flag-VP16C-SXRtransfected MG63 cells. In this population, we excluded genes up-regulated with the ratios of fold change in Flag-VP16C-SXR cells versus vector cells by $\geq 1 \cdot 5$-fold, as we considered that such genes were SXR dependent.

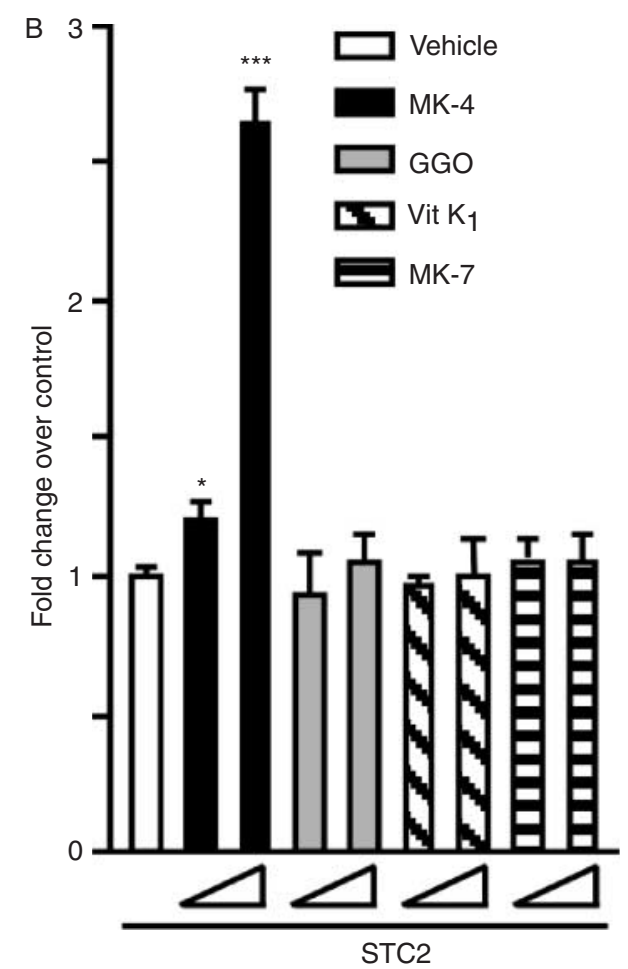

Figure 2 Specificity of MK-4 for induction of GDF15 and STC2 mRNA expression in osteoblastic cells. MG63 cells were treated with 5 or $10 \mu \mathrm{M}$ of vitamin $\mathrm{K}_{1}, \mathrm{MK}-4, \mathrm{MK}-7$, or geranylgeraniol (GGO) for $72 \mathrm{~h}$. mRNA levels for GDF15 (A) and STC2 (B) were determined by qRT-PCR. Data are representative of experiments with similar results, each performed in triplicate. ${ }^{\star} P<0.05,{ }^{\star \star} P<0.01,{ }^{\star \star \star} P<0.001$ when compared with control cells treated with vehicle. 
Flag-VP16C-SXR was constructed previously that could provide more intense SXR ligand-dependent signals when compared with the original SXR plasmid (Ichikawa et al. 2006). We used Flag-VP16C-SXR as it was useful to exclude SXR-dependent genes from the SXR-independent gene group. Through this procedure, 15 transcripts from 14 distinct genes were selected as MK-4 targets that were potentially independent of SXR pathways (Table 1). We focused on GDF15 and a secreted peptide hormone STC2 as putative bone-related genes for further experiments.

\section{Induction of GDF15 and STC2 specifically by MK-4 in osteoblastic cells}

We validated whether mRNA expression levels for these two genes could be modulated by MK-4 in parental MG63 cells using quantitative RT-PCR (qRT-PCR) analysis. In proliferating culture of MG63 cells, the significant induction of both GDF15 and STC2 was detected after 48-h treatment with MK-4 (Fig. 1A). GDF15 and STC2 were also induced in mouse osteoblastic MC3T3-E1 cells after 48-h treatment with MK-4 (Fig. 1B).

We next investigated whether GDF15 and STC2 were induced by other vitamin Ks or the MK-4 side chain structure GGO. Induction of GDF15 and STC2 mRNA by vitamin $\mathrm{K}_{1}$, MK-7, or GGO was compared with that by MK-4. MK- 4 of 5 and $10 \mu \mathrm{M}$ significantly up-regulated the $M K-4$ target genes, whereas the others had no effect (Fig. 2).

\section{Up-regulation of $M K-4$ target genes in a GGCX and SXR-independent manner}

Since $M K-4$ target genes were not induced by vitamin $\mathrm{K}_{1}$ or MK-7, we next sought to verify that a GGCXmediated pathway does not participate in the induction of these $M K-4$ target genes. We investigated the effects of a siRNA against GGCX on the ligand-dependent induction of gene expression. Ninety-six-hour treatment with the specific siRNA duplex against GGCX $(70 \mathrm{nM})$, but not with a control siRNA directed against luciferase, reduced the GGCX mRNA level by more than $80 \%$ in MG63 cells (Fig. 3A). In that cell system, the GGCX siRNA had no effects in MK-4-activated mRNA expression for GDF15 and STC2 (Fig. 3B). We next examined whether the SXR pathway was involved in the regulation of GDF15 and STC2 mRNA expression using MG63/Flag-VP16C-SXR cells. In cells stably expressing SXR, mRNA encoding the $S X R$ target gene CYP3A4 was induced in $24 \mathrm{~h}$ by treatment with MK-4 or the SXR agonist RIF. In contrast, GDF15 and STC2 were up-regulated after 48-h treatment with MK-4 but not with RIF (Fig. 4A and B).

\section{PKA is an activator for the induction of $M K-4$ target genes in osteoblastic cells}

It has been shown that the modulation of transcriptional activities by PKA phosphorylation is one of the key events in osteoblasts, such as through parathyroid hormone or $\beta 2$-adrenergic receptor pathways (Selvamurugan et al. 2000, Elefteriou et al. 2005). There is a report that MK-4 might modulate gene expression and activate transcriptional factor activities in a PKAdependent manner in a hepatocellular carcinoma cell line (Otsuka et al. 2004). Thus, we questioned whether PKA activity was responsible for the up-regulation of GDF15 and STC2 by MK-4 in osteoblastic cells. MK-4 $(10 \mu \mathrm{M})$ markedly induced phosphorylation of PKA in MG63 cells from 2 to $24 \mathrm{~h}$ after the stimulation (Fig. 5A). In experiments of PKA activation by FSK $(10 \mathrm{nM})$, the mRNA expression of GDF15 and STC2 was significantly up-regulated after 48-h treatment (Fig. 5B).

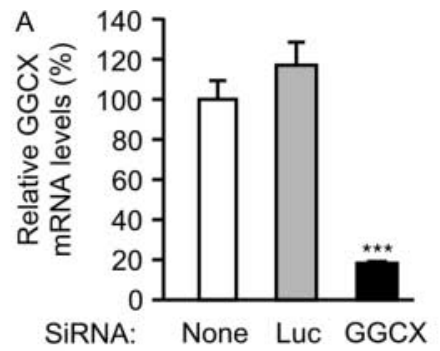

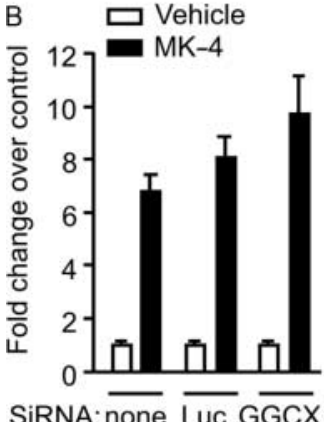

mRNA:

\section{GDF15}

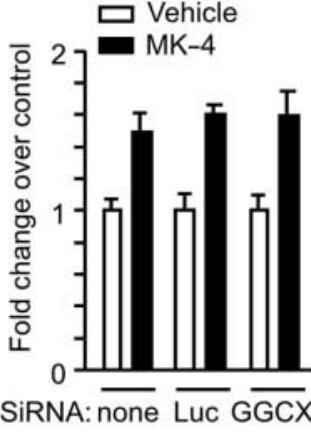

mRNA: $\quad$ STC2
Figure 3 GDF15 and STC2 were up-regulated by a GGCXindependent pathway in osteoblastic cells. (A) MG63 cells were transfected with GGCX siRNA (70 nM) for $96 \mathrm{~h}$, and mRNA expression of GGCX was determined by qRT-PCR. Data represent percentages of mRNA levels using the value with Luc siRNA treatment as $100 \%$. (B) Effects of GGCX siRNA on MK-4induced up-regulation of GDF15 and STC2. At $24 \mathrm{~h}$ after transfection of GGCX siRNA, MG63 cells were treated with MK-4 $(10 \mu \mathrm{M})$ for $72 \mathrm{~h}$ and mRNA expression was determined by qRTPCR. Data represent fold changes in mRNA over vehicle treatment. ${ }^{* \star} P<0.001$ when compared with control cells with no siRNA treatment. 

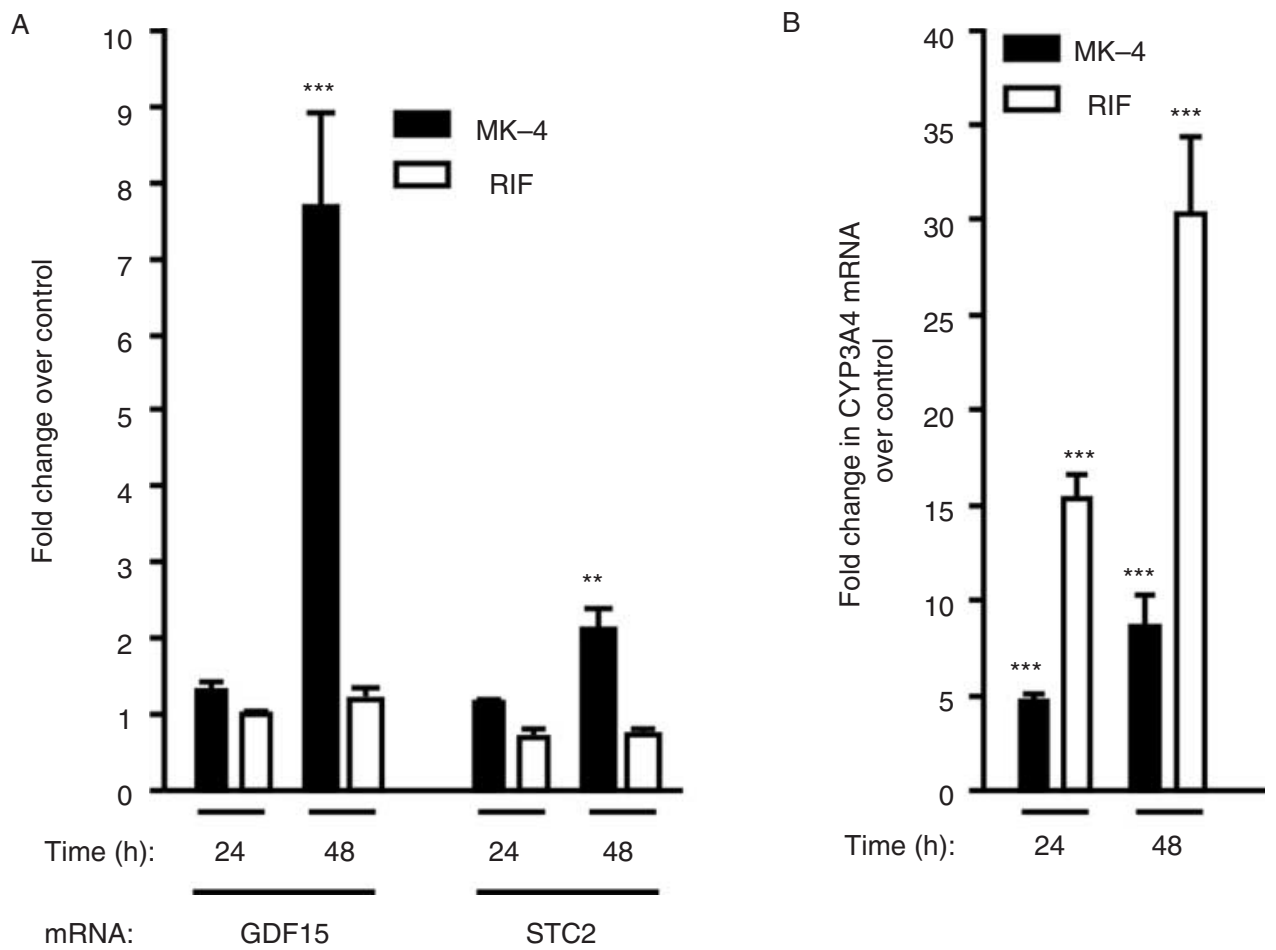

Figure 4 GDF15 and STC2 were up-regulated in an SXR-independent manner in osteoblastic cells. MG63/Flag-VP16C-SXR cells were treated with MK-4 $(10 \mu \mathrm{M})$, rifampicin (RIF, $10 \mu \mathrm{M})$, or vehicle for 24 or $48 \mathrm{~h}$, and mRNA expression was determined by qRT-PCR. (A) GDF15 and STC2 mRNA levels. (B) CYP3A4 mRNA levels. Data are representative of experiments with similar results, each performed in triplicate. ${ }^{* \star} P<0.01,{ }^{* *} P<0.001$ when compared with control cells treated with vehicle.

Because it was likely that PKA activity was related to the transcriptional regulation of GDF15 and STC2, we further investigated whether the loss of function of PKA might affect the expression of GDF15 and STC2. Using a specific PKA inhibitor H89 $(10 \mu \mathrm{M})$ for $72 \mathrm{~h}$, MK-4dependent up-regulation of these two genes was reduced by $\sim 30 \%$ (Fig. $6 \mathrm{~A}$ ). We also performed the knockdown study of PRKACA in MG63 cells using a specific siRNA duplex (Fig. 6B and C). In a condition of $>60 \%$ reduction of PRKACA mRNA levels by siPKA compared with the control siRNA against luciferase, MK-4-dependent up-regulation of GDF15 and STC2 was reduced by 45 and $30 \%$ respectively.

\section{Discussion}

We previously reported that SXR mediated the transcriptional regulation of several osteoblastic marker genes by the vitamin $\mathrm{K}_{2}$ congener MK-4 (Tabb et al. 2003). In the present study, we identified GDF15 and STC2 as novel vitamin $\mathrm{K}_{2}$ target genes up-regulated only by MK-4 in an SXR-independent manner in osteoblastic cells. The expression of both GDF15 and STC2 genes was markedly induced by MK-4 after 48-h treatment, whereas vitamin $\mathrm{K}_{1}$, MK-7, GGO, and the SXR agonist RIF were not effective in inducing the expression of the genes. Furthermore, siRNA against GGCX did not affect the up-regulation of GDF15 and STC2 gene expression by MK-4. These results suggested that induction of GDF15 and STC2 was specific for MK-4 in osteoblastic cells, and that this induction was mediated by SXR- and GGCX-independent pathway(s).

GDF15 belongs to the superfamily of transforming growth factor- $\beta$, and it is generated as a $40 \mathrm{kDa}$ propeptide from which the N-terminus is cleaved and a $30 \mathrm{kDa}$ disulfide-linked dimeric protein is secreted as the active form (Bootcov et al. 1997). It was first named macrophageinhibiting cytokine 1 (Bootcov et al. 1997) or placental bone morphogenetic protein (Hromas et al. 1997), and also later named prostate-derived factor (Paralkar et al. 1998) or non-steroidal anti-inflammatory drug-activated gene (Baek et al. 2001). GDF15 is abundantly expressed in placenta and mildly expressed in liver and prostate at baseline, but many tissues show the dramatic induction of expression following various stimuli such as cytokine, growth factor, or hypoxia (Bootcov et al. 1997, Albertoni et al. 2002, Nazarova et al. 2004, Schlittenhardt et al. 2004). It has been shown that several kinases and transcriptional factors may contribute to the regulation of GDF15 


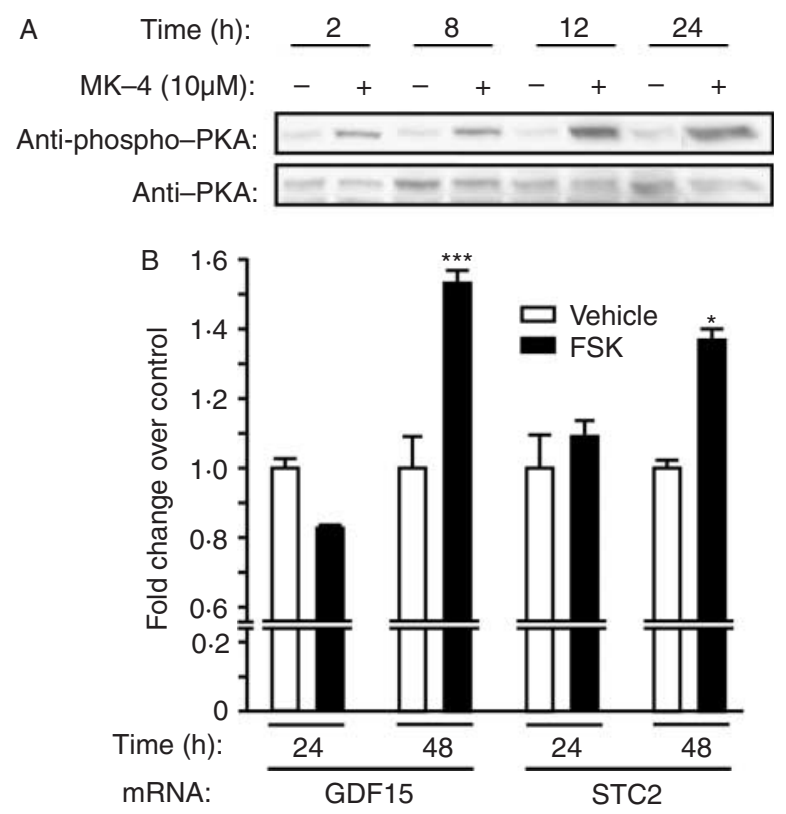

Figure 5 Phosphorylation of protein kinase $A(P K A)$ by MK-4 and induction of GDF15 and STC2 mRNA by a PKA activator. (A) MG63 cells were treated with MK-4 $(10 \mu \mathrm{M})$ or vehicle $(\mathrm{MK}-4$,$) for the$ indicated times. Whole cell lysates were separated by SDS-PAGE, and phosphorylated PKA was detected by immunoblot analysis using anti-phospho-PKA antibody. The identical membrane was re-probed with whole PKA antibody (anti-PKA). (B) MG63 cells were treated with forskolin (FSK, $10 \mathrm{nM}$ ) or vehicle $(0.1 \% \mathrm{DMSO})$ for the indicated times. mRNA levels for GDF15 and STC2 were determined by qRT-PCR. Data are representative of experiments with similar results, each performed in triplicate. ${ }^{*} P<0.05$,

${ }^{* *} P<0.001$ when compared with control cells treated with vehicle.

expression, including p53 (Li et al. 2000, Tan et al. 2000), protein kinase C (Shim \& Eling 2005), phosphatidylinositol 3-kinase/AKT (Yamaguchi et al. 2004), or early growth response 1 (EGR-1; Baek et al. 2005). The transcriptional regulation by PKA has not been definitely shown previously, yet it is likely that PKA is involved in GDF15 regulation as the gene expression was induced by dibutyryl cAMP in murine preadipocytes (Uldry et al. 2006). Although PKA sometimes phosphorylates p53, it is unlikely that p53 is responsible for the modulation of GDF15 expression in MG63 cells as the cell line has been shown to lack p53 (Masuda et al. 1987, Diller et al. 1990).

Regarding the physiological significance of GDF15 in bone-related tissues, the gene may play a role in the developmental stage as it has been shown to be expressed in the skin and in the cartilaginous tissue in the 18-dpc rat embryos (Paralkar et al. 1998). Similar to the function of bone morphogenic proteins, s.c. implantation of recombinant GDF15 protein ectopically induced the cartilage and immature endochondral bone formation (Paralkar $e t$ al. 1998). In prostate cancer, GDF15 expression was expressed only in osseous metastatic lesions, while it was reduced or absent in primary tumor, suggesting that
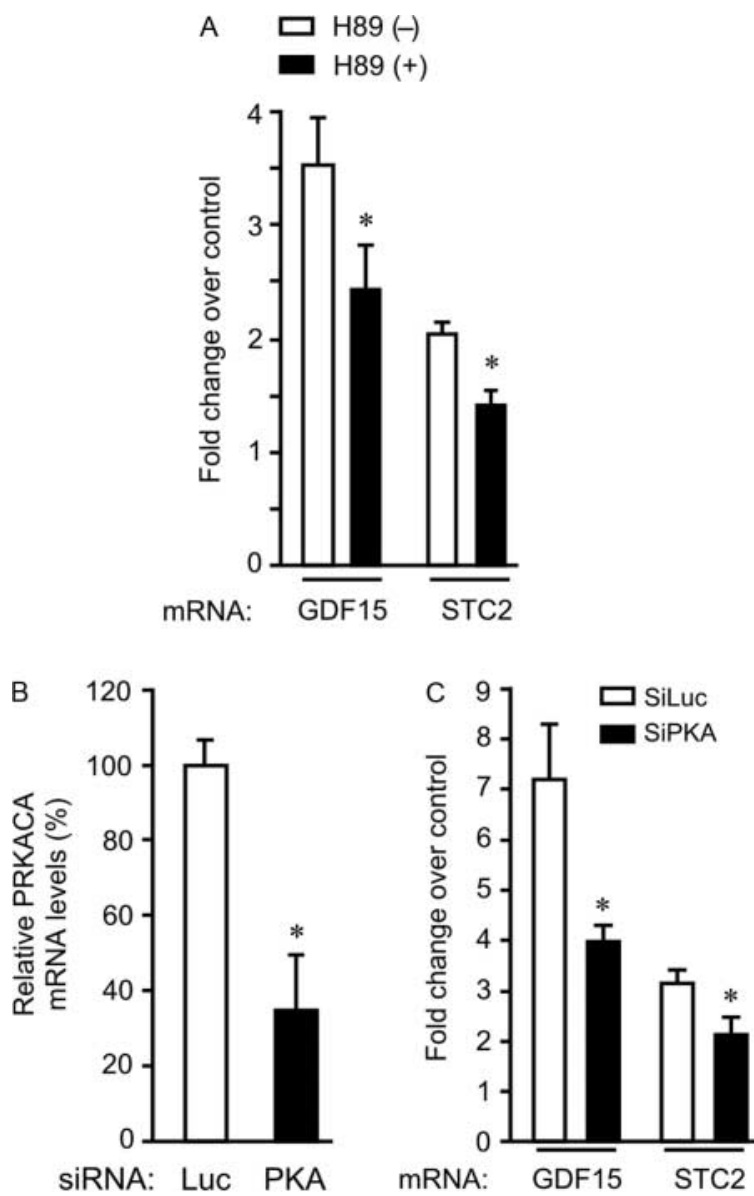

Figure 6 MK-4 induces GDF15 and STC2 in a PKA-dependent manner. (A) MG63 cells were treated with MK-4 $(10 \mu \mathrm{M})$ or vehicle in the presence or absence of $\mathrm{H} 89(10 \mu \mathrm{M})$ for $72 \mathrm{~h}$. mRNA levels for GDF15 and STC2 were determined by qRT-PCR. (B) MG63 cells were transfected with siRNAs $(14 \mathrm{nM})$ that target either $\alpha$-catalytic subunit of PKA, PRKACA (siPKA), or luciferase (siLuc) for $72 \mathrm{~h}$. PRKACA mRNA expression was determined by qRT-PCR. (C) Effects of siPKA on MK-4-dependent up-regulation of GDF15 and STC2. Cells were transfected with siRNAs (14 nM) and incubated with MK-4 $(10 \mu \mathrm{M})$ or vehicle for $72 \mathrm{~h}$. Data are representative of experiments with similar results, each performed in triplicate. ${ }^{*} P<0.05$ when compared with control cells treated with vehicle test.

GDF15 expression might be linked to the osteoblastic phenomena associated with bone metastasis (Thomas et al. 2001). GDF15 also has modulating effects on cell adhesion or proliferation (Li et al. 2000, Tan et al. 2000, Nazarova et al. 2004). As MK-4 has been known as a modulator of cell proliferation in osteoblastic cells (Akedo et al. 1992) and hepatocellular carcinoma cells (Otsuka et al. 2004), GDF15 might be also involved in this growth-regulatory function of MK-4.

STCs represent a small family of secreted glycoprotein hormones, consisting of STC1 and STC2, which has been conserved from fish to mammals. It was assumed that mammalian STC would mimic the function of fish STC-1 in mineral homeostasis (Olsen 
et al. 1996, Wagner et al. 1997, Madsen et al. 1998). STC1 is expressed in osteoblastic cells and could be induced during osteoblastic differentiation of rat fetal calvaria cells (Yoshiko et al. 1999, 2003). Overexpression and knockdown study of STC1 led to the acceleration and retardation of osteogenic development respectively (Yoshiko et al. 2003). STC1 is also expressed in chondrocytes and may also stimulate chondrocyte proliferation in cartilage matrix (Jiang et al. 2000, Filvaroff et al. 2002). In transgenic mice expressing human STC2, growth restriction and developmental retardation were observed in both prenatal and postnatal stages, and ossification was reduced in different endochondral skeletal elements (Gagliardi et al. 2005). Systemic overexpression of human STC1 in transgenic mice, however, also exhibited postnatal growth retardation (Varghese et al. 2002) and reduced ossification in cranial bones (Gagliardi et al. 2005), suggesting the discrepancy between animal models and culture cells. More specific studies targeting osteoblast and chondrocyte lineage will be required for better understanding of the STC physiology in bone development and formation, yet STC could be one of the key factors for the regulation of bone homeostasis. Interestingly, it has been shown that STC2 is closely related to steroid hormone physiology, as its expression is induced by estrogen (Charpentier et al. 2000, Bouras et al. 2002), or it has an inhibitory effect on FSHinduced progesterone production in rat ovary granulose cells (Luo et al. 2005). It is likely that STC2 could play a paracrine role also in bone formation.

In this study, we investigated the effects of PKA on GDF15 and STC2 expression in osteoblastic cells and demonstrated that PKA was responsible, at least in part, for the MK-4-dependent up-regulation of these two genes. It has been reported that MK-4 activated transcriptional factors activating enhancer-binding protein $2 \alpha$ (AP-2), upstream stimulatory factor (USF), and cyclic adenosine monophosphate response element-binding protein (CREB), and PKA activity might be stimulated by MK-4 in hepatocellular carcinoma cell line HepG2 (Otsuka et al. 2004). The activation of PKA by FSK in the present study mimicked the MK-4-induced up-regulation of GDF15 and STC2 in osteoblastic cells, although it is not clear whether MK-4 directly increases cyclic AMP production. It is also possible that PKA is phosphorylated by MK-4 through a cAMP-independent pathway, such as the one mediated by sphingosine (Ma et al. 2005). Future study will reveal the molecular details of MK-4-induced PKA activity in osteoblastic cells. It might be also interesting to investigate whether the MK-4-dependent PKA activation is important in other non-osteoblastic cells.

Here, we have shown that the PKA-dependent pathway is involved in the regulation of $M K-4$ target genes in osteoblastic cells in an SXR- and GGCX-independent manner. Our data suggest that GDF15 and STC2 are novel $M K-4$ target genes up-regulated by the PKA-dependent pathway. Induction of GDF15 and STC2 at proliferation stage and post-confluent phase in osteoblastic cells might affect osteogenesis and chondrogenesis via autocrine or paracrine mechanisms.

\section{Acknowledgements}

We thank T Suzuki and R Nozawa for their technical assistance. This work was supported in part by grantsin-aid from the Ministry of Health, Labor and Welfare, the Promotion and Mutual Aid Corporation for Private Schools of Japan, the Japan Society for the Promotion of Science, and the NIH (GM-60572 to BB). This work was supported in part by a grant of the Genome Network Project from the Ministry of Education, Culture, Sports, Science and Technology of Japan. The authors declare that there is no conflict of interest that would prejudice the impartiality of this scientific work.

\section{Disclosure}

The authors have nothing to declare.

\section{References}

Akedo Y, Hosoi T, Inoue S, Ikegami A, Mizuno Y, Kaneki M, Nakamura T, Ouchi Y \& Orimo H 1992 Vitamin $\mathrm{K}_{2}$ modulates proliferation and function of osteoblastic cells in vitro. Biochemical and Biophysical Research Communications 187 814-820.

Albertoni M, Shaw PH, Nozaki M, Godard S, Tenan M, Hamou MF, Fairlie DW, Breit SN, Paralkar VM, de Tribolet N et al. 2002 Anoxia induces macrophage inhibitory cytokine-1 (MIC-1) in glioblastoma cells independently of p53 and HIF-1. Oncogene 21 4212-4219.

Baek SJ, Kim KS, Nixon JB, Wilson LC \& Eling TE 2001

Cyclooxygenase inhibitors regulate the expression of a TGF- $\beta$ superfamily member that has proapoptotic and antitumorigenic activities. Molecular Pharmacology 59 901-908.

Baek SJ, Kim JS, Moore SM, Lee SH, Martinez J \& Eling TE 2005 Cyclooxygenase inhibitors induce the expression of the tumor suppressor gene EGR-1, which results in the up-regulation of NAG-1, an antitumorigenic protein. Molecular Pharmacology 67 356-364.

Bootcov MR, Bauskin AR, Valenzuela SM, Moore AG, Bansal M, He XY, Zhang HP, Donnellan M, Mahler S, Pryor K et al. 1997 MIC-1, a novel macrophage inhibitory cytokine, is a divergent member of the TGF- $\beta$ superfamily. PNAS 94 11514-11519.

Booth SL, Tucker KL, Chen H, Hannan MT, Gagnon DR, Cupples LA, Wilson PW, Ordovas J, Schaefer EJ, Dawson-Hughes B et al. 2000 Dietary vitamin $\mathrm{K}$ intakes are associated with hip fracture but not with bone mineral density in elderly men and women. American Journal of Clinical Nutrition 71 1201-1208.

Bouras T, Southey MC, Chang AC, Reddel RR, Willhite D, Glynne R, Henderson MA, Armes JE \& Venter DJ 2002 Stanniocalcin 2 is an estrogen-responsive gene coexpressed with the estrogen receptor in human breast cancer. Cancer Research 62 1289-1295.

Charpentier AH, Bednarek AK, Daniel RL, Hawkins KA, Laflin KJ, Gaddis S, MacLeod MC \& Aldaz CM 2000 Effects of estrogen on global gene expression: identification of novel targets of estrogen action. Cancer Research 60 5977-5983. 
Diller L, Kassel J, Nelson CE, Gryka MA, Litwak G, Gebhardt M, Bressac B, Ozturk M, Baker SJ, Vogelstein B et al. 1990 p53 functions as a cell cycle control protein in osteosarcomas. Molecular and Cellular Biology 10 5772-5781.

Elefteriou F, Ahn JD, Takeda S, Starbuck M, Yang X, Liu X, Kondo H, Richards WG, Bannon TW, Noda M et al. 2005 Leptin regulation of bone resorption by the sympathetic nervous system and CART. Nature 434 514-520.

Filvaroff EH, Guillet S, Zlot C, Bao M, Ingle G, Steinmetz H, Hoeffel J, Bunting S, Ross J, Carano RA et al. 2002 Stanniocalcin 1 alters muscle and bone structure and function in transgenic mice. Endocrinology 143 3681-3690.

Gagliardi AD, Kuo EY, Raulic S, Wagner GF \& DiMattia GE 2005 Human stanniocalcin-2 exhibits potent growth-suppressive properties in transgenic mice independently of growth hormone and IGFs. American Journal of Physiology. Endocrinology and Metabolism 288 E92-E105.

Hromas R, Hufford M, Sutton J, Xu D, Li Y \& Lu L 1997 PLAB, a novel placental bone morphogenetic protein. Biochimica et Biophysica Acta 1354 40-44.

Ichikawa T, Horie-Inoue K, Ikeda K, Blumberg B \& Inoue S 2006 Steroid and xenobiotic receptor SXR mediates vitamin $\mathrm{K}_{2}$-activated transcription of extracellular matrix-related genes and collagen accumulation in osteoblastic cells. Journal of Biological Chemistry 281 16927-16934.

Jiang WQ, Chang AC, Satoh M, Furuichi Y, Tam PP \& Reddel RR 2000 The distribution of stanniocalcin 1 protein in fetal mouse tissues suggests a role in bone and muscle development. Journal of Endocrinology 165 457-466.

Li PX, Wong J, Ayed A, Ngo D, Brade AM, Arrowsmith C, Austin RC \& Klamut HJ 2000 Placental transforming growth factor-beta is a downstream mediator of the growth arrest and apoptotic response of tumor cells to DNA damage and p53 overexpression. Journal of Biological Chemistry 275 20127-20135.

Luo G, Ducy P, McKee MD, Pinero GJ, Loyer E, Behringer RR \& Karsenty G 1997 Spontaneous calcification of arteries and cartilage in mice lacking matrix GLA protein. Nature 386 78-81.

Luo CW, Pisarska MD \& Hsueh AJ 2005 Identification of a stanniocalcin paralog, stanniocalcin-2, in fish and the paracrine actions of stanniocalcin-2 in the mammalian ovary. Endocrinology 146 469-476.

Ma Y, Pitson S, Hercus T, Murphy J, Lopez A \& Woodcock J 2005 Sphingosine activates protein kinase A type II by a novel cAMPindependent mechanism. Journal of Biological Chemistry $\mathbf{2 8 0}$ 26011-26017.

Madsen KL, Tavernini MM, Yachimec C, Mendrick DL, Alfonso PJ, Buergin M, Olsen HS, Antonaccio MJ, Thomson AB \& Fedorak RN 1998 Stanniocalcin: a novel protein regulating calcium and phosphate transport across mammalian intestine. American Journal of Physiology 274 G96-G102.

Masuda H, Miller C, Koeffler HP, Battifora H \& Cline MJ 1987 Rearrangement of the $p 53$ gene in human osteogenic sarcomas. PNAS 84 7716-7719.

Nazarova N, Qiao S, Golovko O, Lou YR \& Tuohimaa P 2004 Calcitriolinduced prostate-derived factor: autocrine control of prostate cancer cell growth. International Journal of Cancer 112 951-958.

Nishimoto SK \& Price PA 1985 The vitamin K-dependent bone protein is accumulated within cultured osteosarcoma cells in the presence of the vitamin $\mathrm{K}$ antagonist warfarin. Journal of Biological Chemistry 260 2832-2836.

Olsen HS, Cepeda MA, Zhang QQ, Rosen CA \& Vozzolo BL 1996 Human stanniocalcin: a possible hormonal regulator of mineral metabolism. PNAS 93 1792-1796.

Otsuka M, Kato N, Shao RX, Hoshida Y, Ijichi H, Koike Y, Taniguchi H, Moriyama M, Shiratori Y, Kawabe T et al. 2004 Vitamin $\mathrm{K}_{2}$ inhibits the growth and invasiveness of hepatocellular carcinoma cells via protein kinase A activation. Hepatology 40 243-251.

Paralkar VM, Vail AL, Grasser WA, Brown TA, Xu H, Vukicevic S, Ke HZ, Qi H, Owen TA \& Thompson DD 1998 Cloning and characterization of a novel member of the transforming growth factor- $\beta /$ bone morphogenetic protein family. Journal of Biological Chemistry $\mathbf{2 7 3}$ 13760-13767.

Schlittenhardt D, Schober A, Strelau J, Bonaterra GA, Schmiedt W, Unsicker K, Metz J \& Kinscherf R 2004 Involvement of growth differentiation factor-15/macrophage inhibitory cytokine-1 (GDF15/MIC-1) in oxLDL-induced apoptosis of human macrophages in vitro and in arteriosclerotic lesions. Cell and Tissue Research 318 325-333.

Selvamurugan N, Pulumati MR, Tyson DR \& Partridge NC 2000 Parathyroid hormone regulation of the rat collagenase-3 promoter by protein kinase A-dependent transactivation of core binding factor $\alpha 1$. Journal of Biological Chemistry 275 5037-5042.

Shanahan CM \& Weissberg PL 1998 Smooth muscle cell heterogeneity: patterns of gene expression in vascular smooth muscle cells in vitro and in vivo. Arteriosclerosis, Thrombosis, and Vascular Biology 18 333-338.

Shim M \& Eling TE 2005 Protein kinase C-dependent regulation of NAG-1/placental bone morphogenic protein/MIC-1 expression in LNCaP prostate carcinoma cells. Journal of Biological Chemistry $\mathbf{2 8 0}$ 18636-18642.

Shiraki M, Shiraki Y, Aoki C \& Miura M 2000 Vitamin $\mathrm{K}_{2}$ (menatetrenone) effectively prevents fractures and sustains lumbar bone mineral density in osteoporosis. Journal of Bone and Mineral Research 15 515-521.

Tabb MM, Sun A, Zhou C, Grun F, Errandi J, Romero K, Pham H, Inoue S, Mallick S, Lin M et al. 2003 Vitamin $\mathrm{K}_{2}$ regulation of bone homeostasis is mediated by the steroid and xenobiotic receptor SXR. Journal of Biological Chemistry 278 43919-43927.

Tan M, Wang Y, Guan K \& Sun Y 2000 PTGF- $\beta$, a type $\beta$ transforming growth factor (TGF- $\beta$ ) superfamily member, is a $p 53$ target gene that inhibits tumor cell growth via TGF- $\beta$ signaling pathway. PNAS 97 109-114.

Thomas R, True LD, Lange PH \& Vessella RL 2001 Placental bone morphogenetic protein $(P L A B)$ gene expression in normal, premalignant and malignant human prostate: relation to tumor development and progression. International Journal of Cancer 93 47-52.

Uldry M, Yang W, St-Pierre J, Lin J, Seale P \& Spiegelman BM 2006 Complementary action of the PGC-1 coactivators in mitochondrial biogenesis and brown fat differentiation. Cell Metabolism 3 333-341.

Varghese R, Gagliardi AD, Bialek PE, Yee SP, Wagner GF \& Dimattia GE 2002 Overexpression of human stanniocalcin affects growth and reproduction in transgenic mice. Endocrinology 143 868-876.

Vergnaud P, Garnero P, Meunier PJ, Breart G, Kamihagi K \& Delmas PD 1997 Undercarboxylated osteocalcin measured with a specific immunoassay predicts hip fracture in elderly women: the EPIDOS Study. Journal of Clinical Endocrinology and Metabolism 82 719-724.

Wagner GF, Vozzolo BL, Jaworski E, Haddad M, Kline RL, Olsen HS, Rosen CA, Davidson MB \& Renfro JL 1997 Human stanniocalcin inhibits renal phosphate excretion in the rat. Journal of Bone and Mineral Research 12 165-171.

Yamaguchi K, Lee SH, Eling TE \& Baek SJ 2004 Identification of nonsteroidal anti-inflammatory drug-activated gene $(N A G-1)$ as a novel downstream target of phosphatidylinositol 3-kinase/AKT / GSK-3beta pathway. Journal of Biological Chemistry 279 $49617-49623$.

Yoshiko Y, Son A, Maeda S, Igarashi A, Takano S, Hu J \& Maeda N 1999 Evidence for stanniocalcin gene expression in mammalian bone. Endocrinology 140 1869-1874.

Yoshiko Y, Maeda N \& Aubin JE 2003 Stanniocalcin 1 stimulates osteoblast differentiation in rat calvaria cell cultures. Endocrinology 144 4134-4143.

Received in final form 28 June 2007

Accepted 30 July 2007

Made available online as an Accepted Preprint 2 August 2007 